\title{
THE UNIVERSITY OF MISSOURI
}

ENGINEERING REPRINT SERRES

THE IMPEDANCE OF A COIL PLACED ON A

\section{CONDUCTING PLANE}

\author{
T. J. Russell
}

The Bendix Corporation

Kansas City, Missouri

Columbia, Missouri

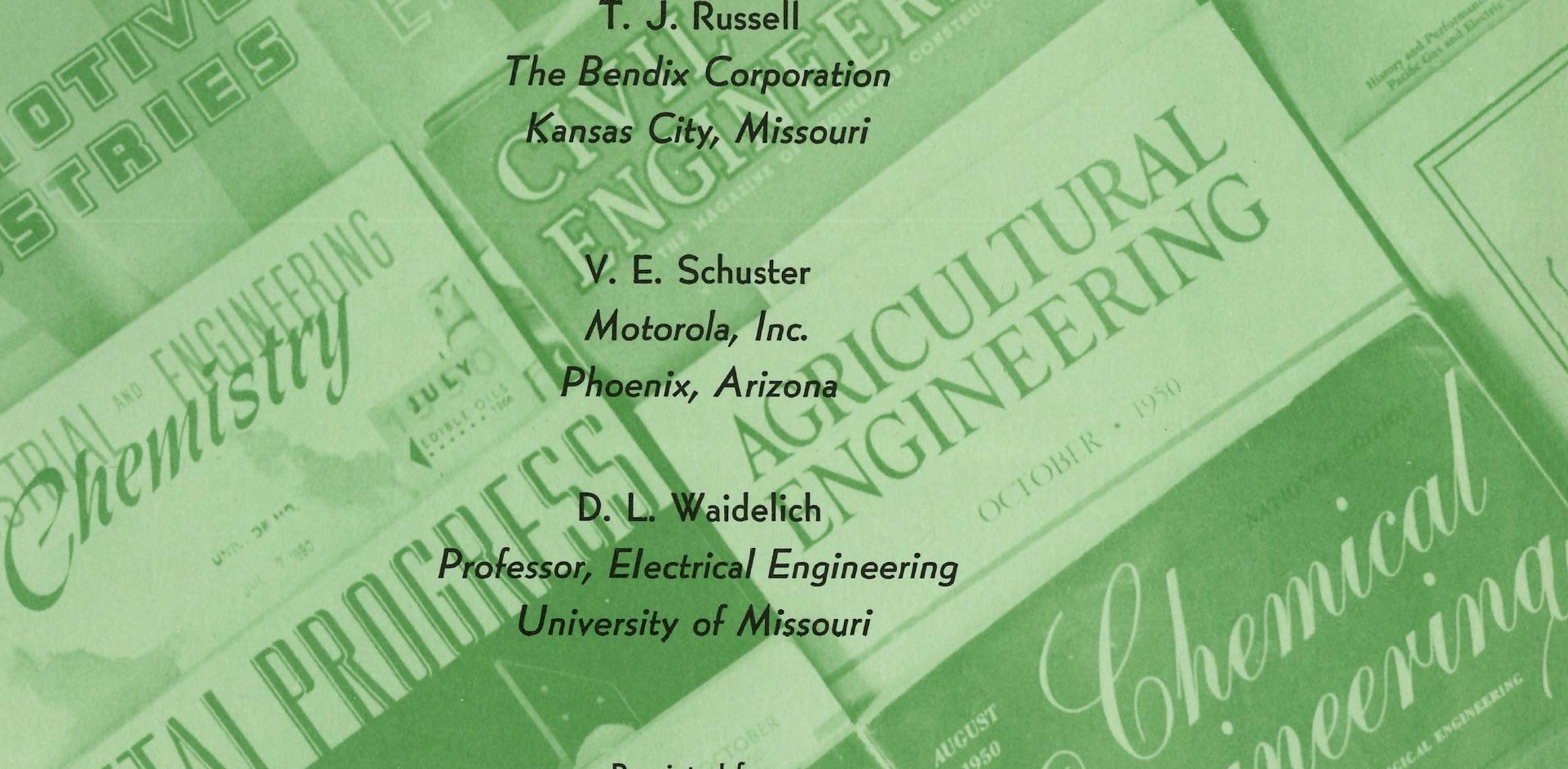

\section{Reprinted from}

AIEE Winter General Meeting, New York, N. Y.

January 28 - February 2, 1962 


\section{COLLEGE OF ENGINEERING \\ THE ENGINEERING EXPERIMENT STATION}

The Engineering Experiment Station was organized in 1909 as a part of the College of Engineering. The staff of the Station includes all members of the Faculty of the College of Engineering, together with Research Assistants supported by the Station Funds.

The Station is primarily an engineering research institution engaged in the investigation of fundamental engineering problems of general interest, in the improvement of engineering design, and in the development of new industrial processes.

The Station desires particularly to co-operate with industries of Missouri in the solution of such problems. For this purpose, there is available not only the special equipment belonging to the Station but all of the equipment and facilities of the College of Engineering not in immediate use for class instruction.

Inquiries regarding these matters should be addressed to:

The Director

Engineering Experiment Station

University of Missouri

Columbia, Missouri

\section{THE UNIVERSITY OF MISSOURI BULLETIN}

Published three times monthly by the University of Missouri, Office of Publications, Columbia, Missouri. Second Class postage paid at Columbia, Missouri. 


\section{The Impedance of a Coil Placed on a Conducting Plane}

\section{T. J. RUSSELL V. E. SCHUSTER \\ D. L. WAIDELICH}

Summary: Probe coils are useful in determining the properties of metals on which the coil is placed. An analysis and an equivalent circuit of the coil on a metal surface are needed and are presented here. The coil was assumed to have a ferromagnetic core, and the constants of the equivalent circuit were computed from the analysis. Experimental measurements of a probe coil on a metal surface, and with varying frequency and conductivity, were made to verify the theory.

ROBE COILS ARE USED for measuring the conductivity of metal

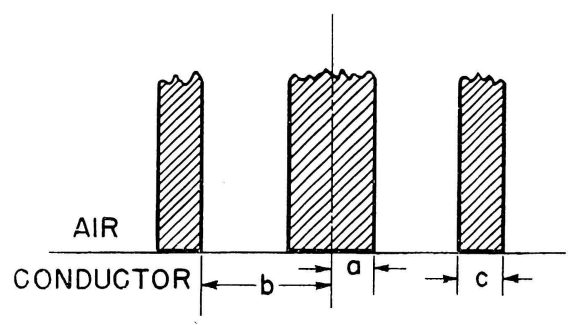

Fig. 1. Cross section of probe core samples, ${ }^{1}$ for testing metal products nondestructively, ${ }^{2}$ and for determining the temperature of metal surfaces. ${ }^{3}$ If the coil is placed near a piece of metal, a varying current in the coil sets up eddy currents in the metal. The eddy currents react on the coil to produce an apparent change of the coil impedance. From this apparent change, various properties of the metal may be deduced. An analysis of a coil near a conductor has been made, 4 although, under the assumptions made, it was found that the solution was inaccurate for small spacings between coil and metal. The present study was made to present theoretical and experimental results for a coil on or very close to a conducting surface.

\section{Theory}

In this study, it was decided to use a coil with a circular cylindrical core of ferromagnetic material whose cross section is shown in Fig. 1. The coil is wound on the central leg of the core, and the magnetic flux is assumed to pass through this leg, enter the metal, and return by way of the outer shell of the core. The core is assumed to have such a high permeability that none of the flux passes through the air and all of it passes through the core and then into the conductor. This is probably the most serious assumption made, and its validity should be checked by the experimental results. Other assumptions made are that the magnetomotive force is zero in the core and that the metal is infinite in extent and depth. The theory is presented in some detail in the Appendix.

The results in the Appendix indicate that the equivalent circuit of the idealized probe coil might consist of a parallel combination of two admittances, $Y_{m}=\left(1 / Z_{m}\right)$ - the apparent admittance of the conductor as viewed from the probe coil, and

Paper 62-18, recommended by the AIEE Special Instruments and Auxiliary Apparatus Committee and approved by the AIEE Technical Operations Department for presentation at the AIEE Winter General Meeting, New York, N. Y., January 28February 2, 1962. Manuscript submitted July 17. 1961; made available for printing October 26, 1961 .

T. J. Russell is with The Bendix Corporation, Kansas City, Mo.; V. E. Schuster is with Motorola, Inc., Phoenix, Ariz., and D. L. WAIDELrCe is with the University of New South Wales, Kensington, N.S.W., Australia.

Part of the theoretical work was done at the Argonne National Laboratory, and the remainder was completed under a National Science Foundation grant to the University of Missouri, Columbia Mo. 
$Z_{A}$

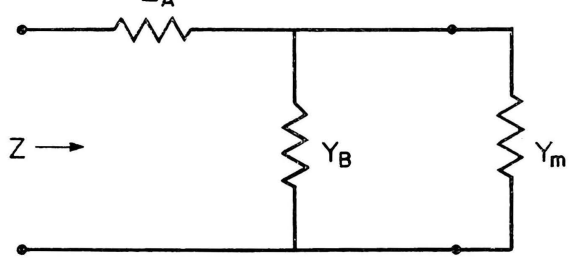

$Y_{p}=\left(1 / Z_{p}\right)$-the admittance of the probe coil except for the apparent admittance of the conductor. An actual probe coil will, in addition, have a series resistance and inductive reactance representing the ohmic resistance of the wire in the coil and the leakage reactance of the coil. The leakage reactance in the actual probe coil would be caused by the magnetic flux lines flowing in the air rather than in the conductor.

Thus, the probe coil equivalent circuit might be taken as that of Fig. 2, which consists of $Y_{m}$ at the output terminals of the 2-terminal pair network shown here as an $L$ network. The admittance $Y_{B}$ would approach $Y_{p}$ as the magnetic permeability of the ferrite core became much greater than that of the conductor and as the leakage flux in the air approached zero. The input impedance is

$Z=Z_{A}+\frac{1}{Y_{B}+Y_{m}}$

The admittance $Y_{m}$ may be obtained from

$Y_{m}=\frac{G(\alpha, \beta, \gamma)}{j \omega \mu b \pi N^{2}}$

where $\omega$ is the angular frequency, $\mu$ is the permeability of the metal in mks (meterkilogram-second) units, $b$ is the dimension of Fig. 1 in meters, and $N$ is the number of turns on the probe coil. The quantity of $G(\alpha, \beta, \gamma)$ is a function of the geometrical shape of the probe, the frequency, and the metal constants, and is given by equation 23 of the Appendix where

Table I. Values of $\mathbf{G}(\alpha, \beta, \gamma)$ for $\alpha=0.47$, $\beta=0.25$

\begin{tabular}{|c|c|}
\hline$|\gamma|$ & $\mathrm{G}(\alpha, \beta, \gamma)$ \\
\hline $\begin{array}{r}0.0 \\
0.1 \\
0.3 \\
1.0 \\
3.0 \\
10.0 \\
30.0 \\
100.0 \\
300.0 \\
1,000.0 \\
3,000.0 \\
10,000.0\end{array}$ & $\begin{array}{c}1.047+\mathrm{j} 0.0 \\
1.047+\mathrm{j} 0.007708 \\
1.048+\mathrm{j} 0.02305 \\
1.052+\mathrm{j} 0.07552 \\
1.079+\mathrm{j} 0.2139 \\
1.231+\mathrm{j} 0.5942 \\
1.678+\mathrm{j} 1.2781 \\
2.782+\mathrm{j} 2.5618 \\
4.688+\mathrm{j} 4.5608 \\
8.477+\mathrm{j} 8.4074 \\
14.644+\mathrm{j} 14.602 \\
26.710+\mathrm{j} 26.685\end{array}$ \\
\hline
\end{tabular}

Fig. 2 (left). L equivalent circuit of probe coil

Fig. 3 (right). Real and imaginary parts of $\mathrm{G}(\alpha, \beta, \gamma)$ for $\alpha=$

$0.47, \beta=0.25$

$\alpha=(a / b)$

$\beta=(c / b)$

$\gamma=j \omega \sigma \mu b^{2}$

An electronic computer has been employed to calculate $G(\alpha, \beta, \gamma)$ over a large range of values of $\alpha, \beta$, and $\gamma$. These values are given by V. E. Schuster and T. J. Russell in two research reports entitled, "The Impedance of a Coil Placed Against a Plane Metal Conductor." A1though unpublished, these reports are available at the Engineering Library, University of Missouri, Columbia, Mo. This library will supply a microfilm or photostatic copy at a nominal cost. Table I gives the values of $G(\alpha, \beta, \gamma)$ for $\alpha=$ 0.47 and $\beta=0.25$ over a large range of the magnitude of $\gamma$, while a plot of these data is shown in Fig. 3. As $\gamma$ approaches zero, the imaginary part of $G(\alpha, \beta, \gamma)$ approaches zero while the real part approaches a value given by equation 25. Physically, this indicates that, with the probe coil resting on a nonconductor, the losses are zero and $Z_{m}$ becomes a pure inductive reactance. As $\gamma$ becomes large, both the real and imaginary parts of $G(\alpha, \beta, \gamma)$ approach each other and become large as indicated in Table $\mathrm{I}$.

Anyone wishing to use values $G(\alpha, \beta$, $\gamma$ ) other than those given in this paper would save much time and effort by using the computed values in the two reports. As shown in the Appendix, the admittance $Y_{m}$ from equation 2 becomes approximately

$Y_{m}=\frac{(1-j) \ln 1 / \alpha)}{2 \sqrt{2} \pi N^{2}} \sqrt{\frac{\sigma}{\mu \omega}}$

This shows that, for the probe coil resting on a good conductor, or a material with high permeability, or for very high frequencies, the admittance has equal real and imaginary parts, similar to the surface admittance of a very thick homogeneous conductor with a plane electromagnetic wave incident on the conductor.

An example of the variation of $G(\alpha, \beta$, $\gamma$ ) with $\alpha$ and $\beta$ is shown in Figs. 4 and 5 where $G(\alpha, \beta, \gamma)=G_{\tau}+j G_{i}$. Fig. 4 pre-

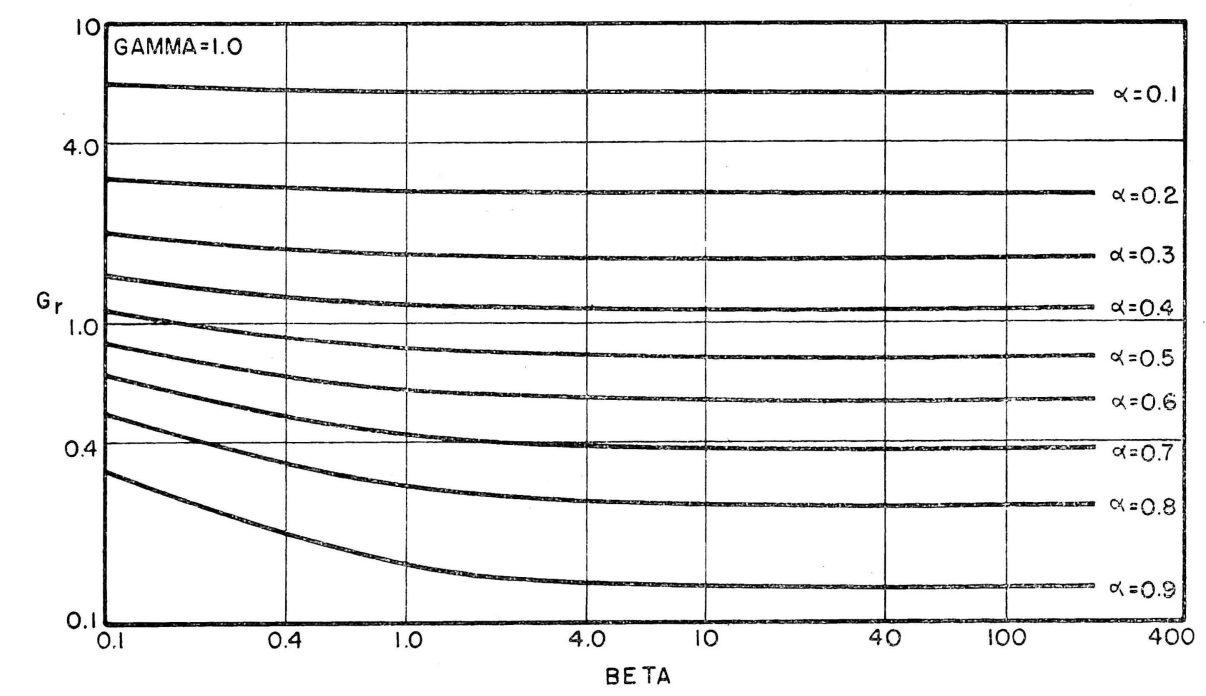

Fig. 4. Real part of $\mathrm{G}(\alpha, \beta, \gamma)$ for $|\gamma|=1.0$ 


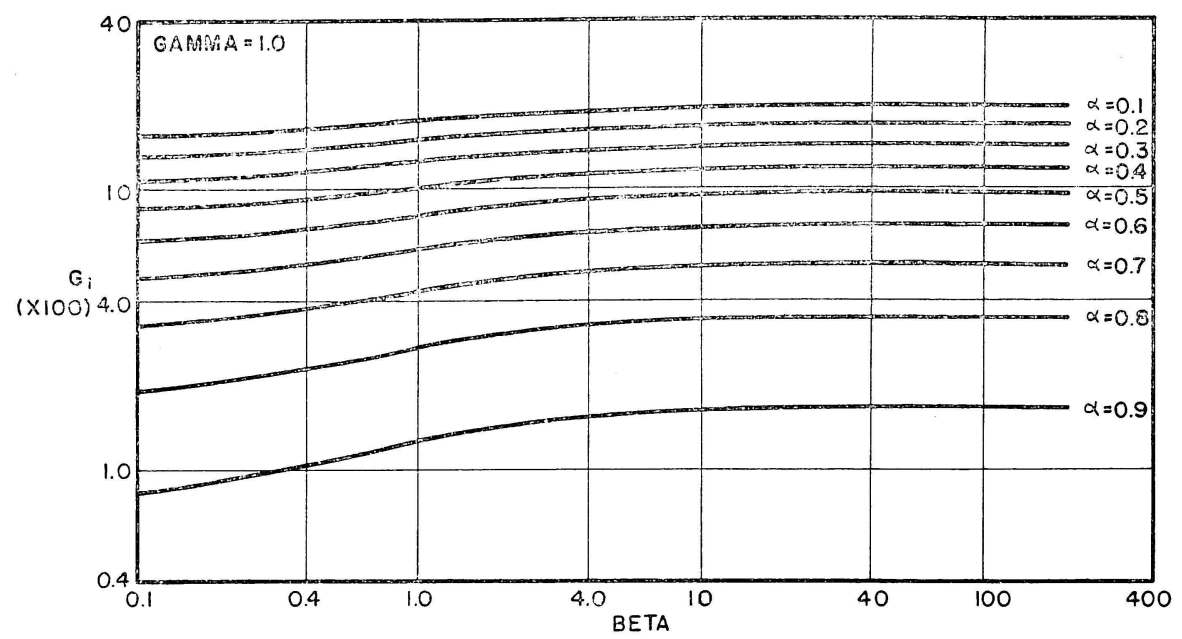

Fig. 5. Imaginary part of $\mathrm{G}(\alpha, \beta, \gamma)$ for $|\gamma|=1.0$

sents the real part $G_{r}$, while Fig. 5 shows the imaginary part $G_{i}$ for the magnitude of $\gamma$ equal to unity. There is practically no change in $G(\alpha, \beta, \gamma)$ when $\beta$ is greater than 10 , and this corresponds to the case of a very thick outer shell on the probe core.

\section{Experimental Work}

The feeling prevailed that experimental work on an actual probe coil placed on various metal plates would help to verify the theory and also point out possible applications. Accordingly a number of ferrite cores were constructed out of commercially available ferrite rods, tubes, and sheets. In addition, several complete ferrite cores were obtained commercially, and the tests on one of these cores will be described. The particular core chosen is shown in Fig. 6 and had
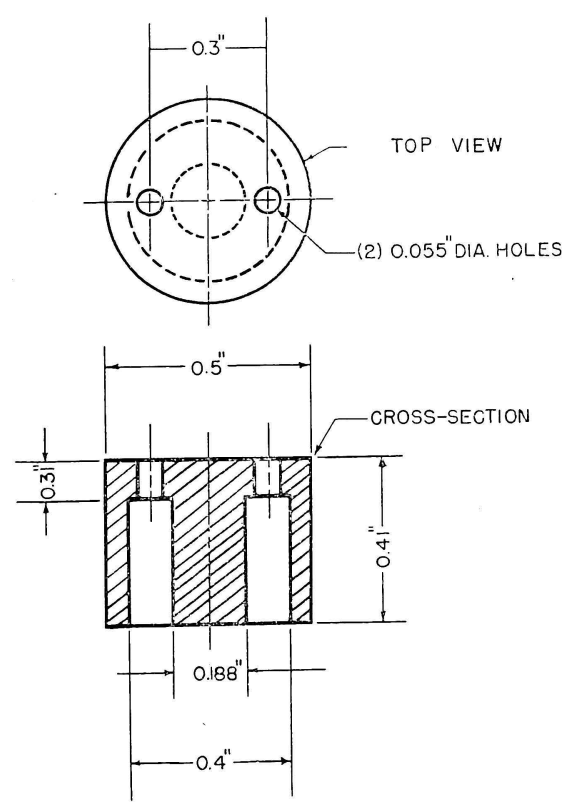

$\alpha=0.47$ and $\beta=0.25$, values of $\alpha$ and $\beta$, the same as those chosen for Table I. The coil consisted of 125 turns of no. 38 copper wire, wound on the center leg of the core.

Metals of various conductivities were obtained in plates about 1 foot square. They were at least $1 / 4$ inch thick, which was sufficient so that, at frequencies of $4 \mathrm{kc}$ and above, the return from the second metal-to-air boundary could be neglected. The conductivities of the metal samples were measured by passing direct current through a piece of known cross-sectional area and measuring the voltage drop across the sample. The conductivities measured are given in Table II.

The measured impedance of the probe coil when placed against a conductor was obtained by use of the bridge circuit of Fig. 7. The quantities to be measured $\left(R_{x}, L_{x}\right)$ were rather low in impedance, so $R_{2}$ was made a 2 -ohm precision resistor. Decade resistors $\left(R_{3}\right)$ and capacitors $\left(C_{3}\right)$ were used along with a precision $0.1-\mu \mathrm{f}$ (microfarad) capacitor at $C_{1}$. A wave analyzer was found to make a good detector. One problem that arises in measurements of this type is that the probe coil overheats because too much power is supplied to the coil. The voltage across the coil was kept below 5 volts for this reason although, if it were made Fig. 6 (left). Experi-
mental probe core

Fig. 7 (right). Circuit to measure impedance of probe coil
Table II. Measured Conductivities

Conductivity, $10^{6}$ Mhos (Units of Conductance)
Per Meter

Metal

B, Stainless Steel............. 1.4

C, Zirconium ................ 2.0

D, Lead........................

E, Tin..................

F, Brass.................

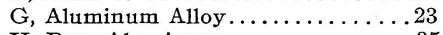

$\mathrm{H}$, Pure Aluminum............. 35

J, Copper.................57

Table III. Calculated Values of $Z_{A}$ and $Y_{B}$

\begin{tabular}{|c|c|c|}
\hline $\begin{array}{c}\text { Frequency, } \\
\text { Kc }\end{array}$ & $Z_{\mathrm{A}}$, Ohms & $\mathrm{Y}_{\mathrm{B}}$, Mhos \\
\hline $\begin{array}{r}4 \ldots \\
8 \ldots \\
16 \ldots\end{array}$ & $\begin{array}{l}5.59+\mathrm{j} 13.05 \\
5.74+\mathrm{j} 26.7 \\
6.48+\mathrm{j} 53.9\end{array}$ & $\begin{array}{l}.009-\mathrm{j} 0.0321 \\
.0035-\mathrm{j} 0.0195 \\
.00143-\mathrm{j} 0.0073\end{array}$ \\
\hline
\end{tabular}

too small, not enough voltage would be available for best operation of the detector. Measurements of the impedance were made at $1-\mathrm{kc}$ intervals from 1 to 16 $\mathrm{kc}$ for each of the metal samples. Fig. 8 shows measured values of $R$ and $\omega L$ where $Z=R+j \omega L$ for three frequencies. The upper curve is for a frequency of $16 \mathrm{kc}$; the middle, $10 \mathrm{kc}$; and the lower, 4 kc. The letters represent the conductors involved: A for air, B for stainless steel, and so on as given in Table II.

\section{Comparison of Theoretical and Experimental Results}

The first step was to determine the impedance $Z_{A}$ and admittance $Y_{B}$ of Fig. 2 at one frequency by using the measured values of the input impedance $Z$ and the theoretically determined values of $Y_{m}$ as taken from equation 2 and Table I. Two measured values of $Z$ and two theoretical values of $Y_{m}$ were needed, and these were taken as those for air and for copper. Air and copper were used because, in the measurement of any other probe coil, these might be the easiest measurements to obtain since they would require only a thick piece of fairly pure copper. Of course, to make the imped- 


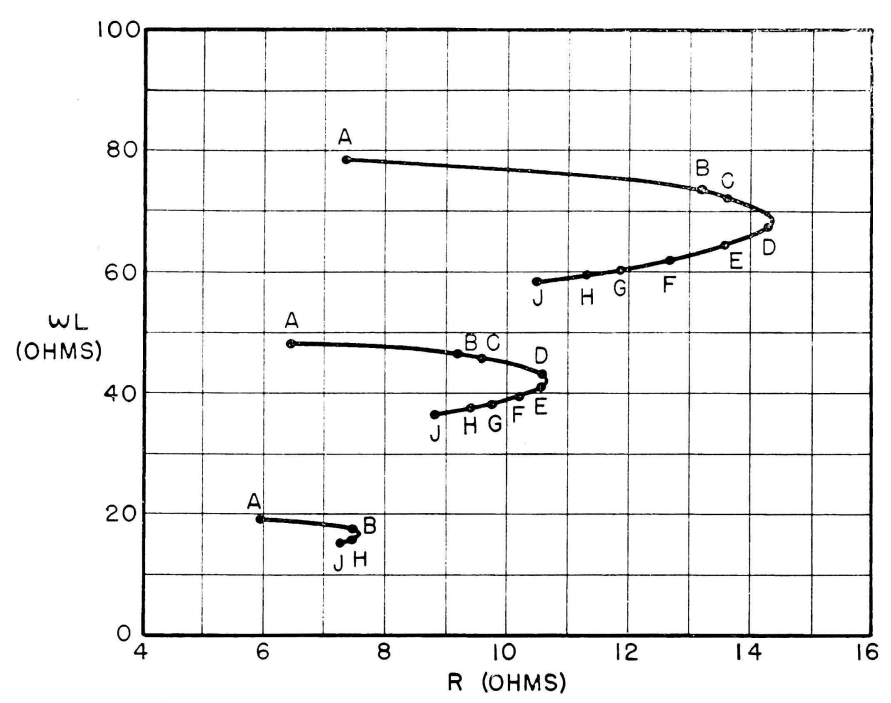

Fig. 8 (left). Measured impedance of probe coil

Fig. 9 (right). Comparison of calculated and measured values of probe-coil impedance, using $L$ equivalent circuit ance measurements, a bridge circuit similar to that of Fig. 7 would be needed. Values of $Y_{m}$ could be obtained from graphs such as Figs. 4 and 5, or the more complete series of values are to be found in the research reports previously mentioned as being available in microfilm or photostatic copies. The length of the tables in these reports has discouraged their publication.

Values of $Z_{A}$ and $Y_{B}$-calculated for 4 , 8 , and $16 \mathrm{kc}$-are given in Table III. The real part of $Z_{A}$ is somewhat greater than the 5.52 ohms resistance of the coil as measured using direct current. The imaginary part of $Z_{A}$ is almost directly proportional to frequency, indicating that it acts much like a constant inductance. The admittance $Y_{B}$, on the other hand, does not appear to have such a simple dependence on frequency and probably depends, for the most part, upon the properties of the ferrite core.

As a further check upon the calculated values of $Y_{m}$, the impedance $Z$ was calculated, using the $Y_{m}$ for each metal as given in equation 2 and Table I, along with the values of $Z_{A}$ and $Y_{B}$ as given in Table III. The results of these calculations for a frequency of $4 \mathrm{kc}$ are shown in Fig. 9, where the scale has been expanded appreciably to bring out the differences between calculated and measured points. The end points for air $(\mathrm{A})$ and copper $(\mathrm{J})$ have the same calculated and measured

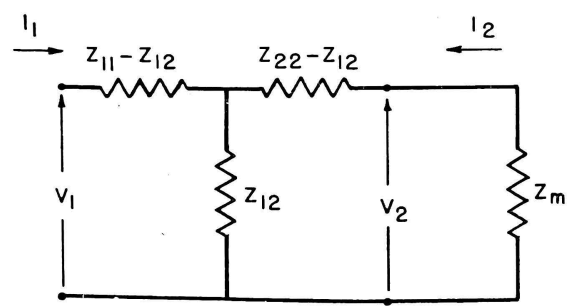

values, but all of the other metals will have calculated and measured values that differ from each other. The metals shown in Fig. 9 are zirconium (C), tin (E), and aluminum alloy (G). The calculated points are the upper ones of each set in Fig. 9, and probably indicate that the variation in inductive reactance for the calculated points is slower than that for the measured points as conductivity is increased. This seemed to indicate that possibly additional impedance between $Y_{B}$ and $Y_{m}$ of Fig. 2 might make the agreement even better.

The equivalent circuit of Fig. 10 was tried as a consequence of this idea. If $Z=\left(V_{1} / I_{1}\right)$,

$Z=\frac{C+A Z_{m}}{B+Z_{m}}$

where

$A=Z_{11}$

$B=Z_{22}$

$C=Z_{11} Z_{22}-Z_{12}^{2}$

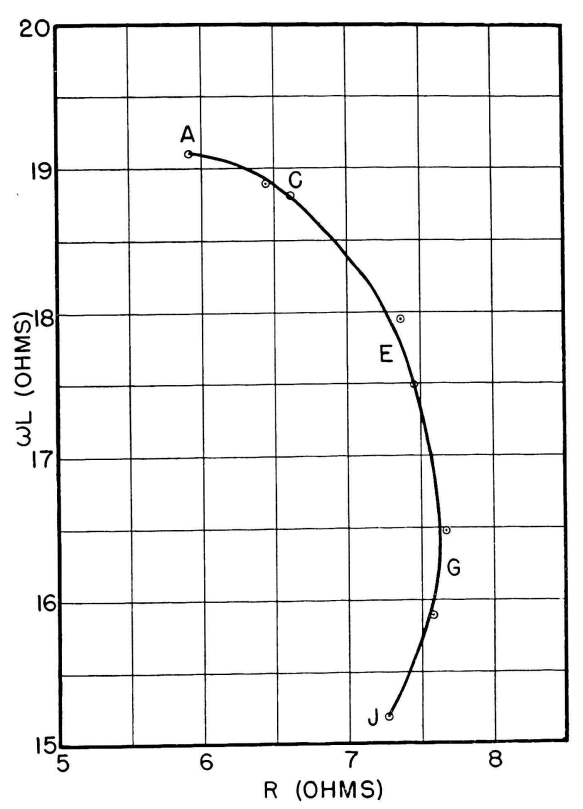

For this equivalent circuit at a given frequency, the three constants $A, B$, and $C$ may be determined by using three different conductivities and the corresponding three pairs of values of $Z$ as measured and $Z_{m}$ as obtained from equation 2. This was done, using stainless steel, aluminum alloy, and copper. At 4 $\mathrm{kc}$, for example, the resulting values of $A, B$, and $C$ are

$A=24.31+j 13.53 \mathrm{ohms}$

$B=23.22-j 8.61 \mathrm{ohms}$

$C=263.2+j 254.9(\mathrm{ohms})^{2}$

When $A, B$, and $C$ from equation 6 are put in equation 5 , the calculated value of $Z$ may be obtained for any conductivity if the corresponding $Z_{m}$ from 2 is also put in 5 . The results of these calculations for four different frequencies are shown in Figs. 11 and 12. Again the scales have been expanded substantially so that
Fig. 10 (left). T equivalent circuit of probe coil

Fig. 11 (right). Same as Fig. 9, except resistance is compared, using $T$ equivalent circuit

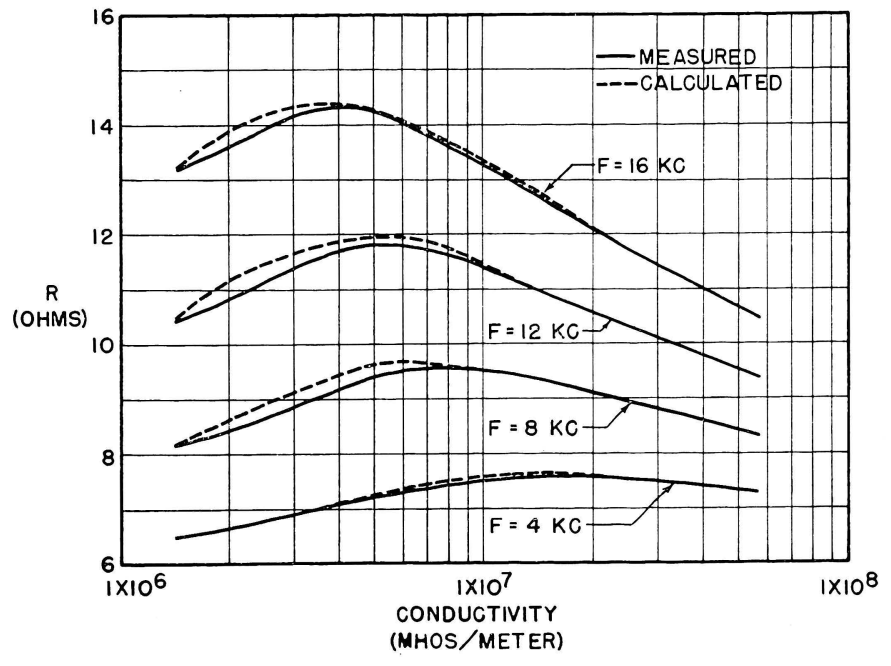




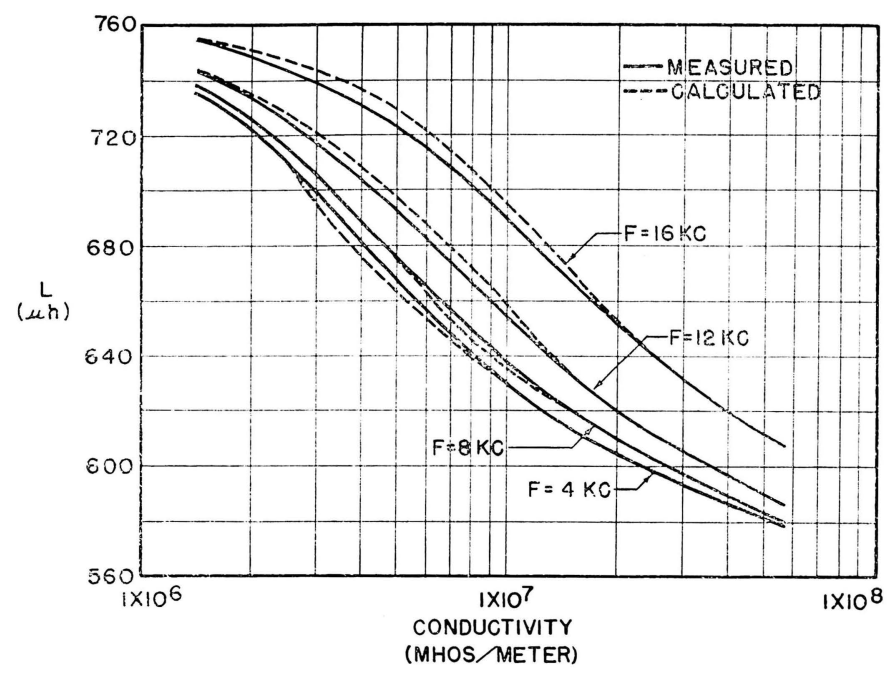

measured and calculated differences are clearly distinguishable.

\section{Conclusions}

A method of analysis for a probe coil with a ferrite core has been presented, along with some of the calculated results. Some experimental measurements have also been presented and compared with the calculated results by means of two equivalent circuits for the probe. This information should be useful in designing probe coils and in planning electronic circuitry associated with the coils. Extensions of this analysis and experimental work would be helpful in connection with:

1. Probe coils separated by air or nonmetallic material from a conducting surface.

2. Probe coils with air as the core.

3. Pulsed probe coils.

4. Probe coils over a conductor with layers of different conductivities.

\section{Appendix. Derivation of the Coil Equations}

From Fig. 1, the magnetic field intensity $H_{Z}$ in the $Z$ direction in the conductor may be obtained from the following wave equation:

$$
\nabla^{2} H_{z}=\sigma \mu p H_{z}
$$

where $\nabla^{2}$ is the Laplacian; $\sigma$ and $\mu$ are the conductivity and permeability, respectively, of the conductor; $p=j \omega=j 2 \pi f$; and $f$ is the frequency of the sinusoidal wave of current flowing in the coil. The $Z$ axis is the same as the axis of the core with the positive direction of the axis pointing from the conductor toward the core. From equation 7, using cylindrical co-ordinates

$$
H_{z}=g e^{k_{1} z} J_{0}\left(k_{2} r\right)
$$

where $g$ and $k_{1}$ are arbitrary constants, $J_{0}$ is the Bessel function of the first kind of zero order, and
Fig. 12. Same as Fig. 9, except inductance is compared, using $T$ equivalent circuit

$$
k_{2}^{2}=k_{1}^{2}-\sigma \mu p
$$

The other field components may be obtained from Maxwell's equations

$H_{r}=-\frac{g k_{1}}{k_{2}} e^{k_{1} z} J_{1}\left(k_{2} r\right)$

$E=-\frac{g \mu p}{k_{2}} e^{k_{1} z} J_{1}\left(k_{2} r\right)$

where $J_{1}$ is the Bessel function of the first order.

To satisfy the boundary conditions, using equation 8 , put $H_{z}$ in the form of the following equation:

$H_{z}=\int_{0}^{\infty} g(\lambda) e^{k z} J_{0}(\lambda r) \lambda d \lambda$

where $k=\sqrt{\lambda^{2}+\sigma \mu p}, \lambda$ is a variable of integration, and $g(\lambda)$ is an arbitrary function. Similarly, for the other field components

$H_{\tau}=-\int_{0}^{\infty} g(\lambda) k e^{k z} J_{1}(\lambda r) d \lambda$

$E=-p \mu \int_{0}^{\infty} g(\lambda) e^{k z} J_{1}(\lambda r) d \lambda$

The field components indicate that eddy currents in the conductor are circular, are in planes perpendicular to the $Z$ axis, and have their centers on this axis. Next it was assumed that the total magnetic flux in the center leg of the core was $\Phi$ and that the flux density was the same everywhere over the cross section of this leg. The flux density in the center leg is then

$\Phi / \pi a^{2}$

and in the outer shell

$\Phi / \pi\left[(b+c)^{2}-b^{2}\right]=\Phi / \pi c(2 b+c)$

where $a, b$, and $c$ are dimensions as shown in Fig. 1. Using equations 11,13 , and 14 , the magnetic field intensity in the $Z$ direction at the surface of the conductor is

$$
\begin{aligned}
H_{z} \mid z=0 & =\int_{0}^{\infty} g(\lambda) J_{0}(\lambda r) \lambda d \lambda \\
& =\left\{\begin{array}{c}
-\Phi / \mu \pi a^{2}, 0<r<a \\
0, a<r<b \\
\Phi / \mu \pi c(2 b+c), b<r<(b+c) \\
0,(b+c)<r
\end{array}\right.
\end{aligned}
$$

where $\mu$ is the permeability of the conductor. Equation 15 is in the form of a Hankel transform. ${ }^{5}$ The inverse transform of 15 is as follows

$$
\begin{aligned}
g(\lambda) & =\int_{0}^{\infty}\left[H_{z} \mid z=0\right] J_{0}(\lambda r) r d r \\
= & \frac{\Phi}{\mu \pi}\left\{-\frac{J_{1}(\lambda a)}{(\lambda a)}+\frac{(b+c)^{2}}{c(2 b+c)} \frac{J_{1}[\lambda(b+c)]}{\lambda(b+c)}-\right. \\
& \left.\frac{b^{2}}{c(2 b+c)} \frac{J_{1}(\lambda b)}{(\lambda b)}\right\}
\end{aligned}
$$

The magnetomotive force $N I$ is found by integrating the magnetic field intensity around a closed path, or

$$
N I=\int_{a}^{b}\left(\left.H_{r}\right|_{z=0}\right) d r+(N I)_{\text {probe }}
$$

The first integral is the magnetomotive force for the conductor, while the second term is that for the ferrite core of the probe coil. Assuming the resistance of the coil is zero for the moment, the admittance $Y$ of the probe coil is

$Y=\frac{\frac{1}{N} \int_{a}^{b}\left(\left.H_{\tau}\right|_{z=0}\right) d r+\frac{(N I)_{\text {probe }}}{N}}{N j \omega \Phi}=Y_{m}+Y_{p}$

where $N j \omega \Phi$ is the voltage across the coil, $Y_{m}$ is the portion of the admittance ascribable to the conductor, and $Y_{p}$ that for the coil itself. Then

$Y_{m}=\frac{1}{j \omega \Phi N^{2}} \int_{a}^{b}\left(H_{r} \mid z=0\right) d r$

From equations 12 and 16

$$
\begin{aligned}
\left.H_{r}\right|_{z=}= & \frac{\Phi}{\mu \pi}\left\{\int_{0}^{\infty} k \frac{J_{1}(\lambda a)}{\lambda a} J_{1}(\lambda r) d \lambda-\right. \\
& \frac{(b+c)^{2}}{c(2 b+c)} \int_{0}^{\infty} k \frac{J_{1}[\lambda(b+c)]}{\lambda(b+c)} J_{1}(\lambda r) d \lambda+ \\
& \left.\frac{b^{2}}{c(2 b+c)} \int_{0}^{\infty} k \frac{J_{1}(\lambda b)}{\lambda b} J_{1}(\lambda r) d \lambda\right\} \quad \text { (20) }
\end{aligned}
$$

Now let

$$
\begin{aligned}
F(\alpha, \delta, \gamma)=\int_{0}^{\infty} & \sqrt{\lambda^{2}+\gamma} J_{1}(\lambda \delta) \times \\
& {\left[J_{0}(\lambda \alpha)-J_{0}(\lambda)\right] \frac{d \lambda}{\lambda^{2}} }
\end{aligned}
$$

$\alpha=(a / b)$

$\beta=(c / b)$

$\gamma=j \omega \sigma \mu b^{2}$

Then, by using equations 19 and 20 and interchanging the order of integration

$$
\begin{aligned}
Y_{m}= & \frac{1}{j \omega \mu b \pi N^{2}}\left[\frac{1}{\alpha} F(\alpha, \alpha, \gamma)-\right. \\
& \frac{(1+\beta)}{\beta(2+\beta)} F(\alpha, 1+\beta, \gamma)+ \\
& \left.\frac{1}{\beta(2+\beta)} F(\alpha, 1, \gamma)\right]
\end{aligned}
$$

where $F(\alpha, \delta, \gamma)$ may be obtained from equation 21 . If

$$
\begin{aligned}
& G(\alpha, \beta, \gamma)=\frac{1}{\alpha} F(\alpha, \alpha, \gamma)- \\
& \frac{1+\beta}{\beta(2+\beta)} F(\alpha, 1+\beta, \gamma)+ \\
& \frac{1}{\beta(2+\beta)} F(\alpha, 1, \gamma)
\end{aligned}
$$


then the apparent impedance introduced by the conductor is

$Z_{m}=\frac{1}{Y_{m}}=\frac{j \omega \mu b \pi N^{2}}{G(\alpha, \beta, \gamma)}$

For the special case of a perfect nonconductor $(\sigma=0, \gamma=0)$ and from equation 23

$$
\begin{gathered}
G(\alpha, \beta, 0)=\frac{2}{\pi \alpha}-\frac{1}{2}\left[{ }_{2} F_{1}\left(\frac{1}{2}, \frac{1}{2} ; 2 ; \alpha^{2}\right)\right]+ \\
\frac{2(1+\beta)}{\pi \beta(2+\beta)}\left[E\left(\frac{1}{1+\beta}\right)-E\left(\frac{\alpha}{1+\beta}\right)\right]+ \\
\frac{2}{\pi \beta(2+\beta)}[E(\alpha)-1]
\end{gathered}
$$

where ${ }_{2} F_{1}\left(1 / 2,1 / 2 ; 2 ; \alpha^{2}\right)$ is a hypergeometric function and is given by the series ${ }^{6,7}$

${ }_{2} F_{1}\left(\frac{1}{2}, \frac{1}{2} ; 2 ; \alpha^{2}\right)=1+\frac{\left(\frac{1}{2}\right)^{2}}{2}\left[\frac{\alpha^{2}}{1 !}\right]+$

$$
\begin{array}{r}
\frac{\left(\frac{1}{2}\right)^{2}\left(\frac{3}{2}\right)^{2}}{2 \cdot 3}\left[\frac{\alpha^{4}}{2 !}\right]+\frac{\left(\frac{1}{2}\right)^{2}\left(\frac{3}{2}\right)^{2}\left(\frac{5}{2}\right)^{2}}{2 \cdot 3 \cdot 4} \times \\
{\left[\frac{\alpha^{6}}{3 !}\right]+\ldots}
\end{array}
$$

and $E(\alpha)$ is the complete elliptic integral of the second kind. ${ }^{8}$

The other important special case is that of a perfect conductor $(\sigma \rightarrow \infty \quad \gamma \rightarrow \infty)$, and from equation 22 , it is found $d^{6,7}$ that when $\sigma$ is very large but finite, the admittance $Y_{m}$ from the same equation is approximately

$$
Y_{m} \approx \frac{(1-j) \ln (1 / \alpha)}{2 \sqrt{2} \pi N^{2}} \sqrt{\frac{\sigma}{\mu \omega}}
$$

\section{References}

1. A Contactless Method for Measurino Specific Impedance and Geometric Dimensions By Means of Eddy Currents, V. P. Grabovetskii.
Automation and Remote Control, New York, N. Y. vol. 20 , July 1959, p. 921.

2. Nondestructive Eddy Current Testino, G. O. McClurg. Transactions, Professional Group on Industrial Electronics, Institute of Radio Engineers, New York, N. Y., vol. IE-11, Dec. 1959, p. 20.

3. An Impedance Bridge for SURface Temperature Measurement, R. J. Mouly. AIEE Transactions, pt. I (Communication and Electronics), vol. 78 , Sept. 1959 , pp. $388-93$.

4. The Impedance of a CoIl Near a Conductor, D. L. Waidelich, C. J. Renken, Jr. Proceedings, National Electronics Conference, Chicago, Ill., vol. 12,1956 , p. 188.

5. Tables of Integral Transforms (book), A. Erdélyi. McGraw-Hill Book Company, Inc., New York, N. Y., 1954, p. 5.

6. Hypergeometric and Legendre Functions with Applications to Integral EQuations of Potential Theory, C. Snow. Applied Mathematics Series 19, National Bureau of Standards, Washington, D. C., 1952, p. 3.

7. A Treatise on the Theory of Besset Functions, G. N. Watson. Cambridge University Press, New York, N. Y., second edition, 1944, pp. $100,401$.

8. Tables of Higher Functions (book), E. Jahnke, F. Emde, F. Lösch. McGraw-Hill Book Company, Inc., 1960, p. 70

A reprint from COMMUNICATION AND ELECTRONICS, published by American Institute of Electrical Engineers 




\section{PUBLICATIONS OF THE ENGINEERING REPRINT SERIES}

Copies of publications may be secured from the Director of the Engineering Experiment Station, University of Missouri. Single copies may be obtained free unless otherwise indicated until the supply is exhausted. Requests for additional copies will be considered upon further inquiry.

Reprint No.

46. The Mutual Impedance of Perpendicular Half-Wave Antennas by D. R. Capps, Assistant Professor of Electrical Engineering, University of Missouri, and D. L. Waidelich, P.E., Prof. of Electrical Engineering, University of Missouri. Reprinted from Proceedings of the National Electronics Conference, Volume XV, Hotel Sherman, Chicago, nlinois, October 13, 14, 15, 1959.

47. The Bandwidth of a Single Layer Absorbing Material by B. W. Sherman, Assistant Instructor, Department of Electrical Engineering, University of Missouri, and D. L. Waidelich, P.E., Professor of Electrical Engineering, University of Missouri. Reprinted from Volume I of the Proceedings of the Second Annual RADC International RAM Symposium 9, 10, and 11 June 1959, Rome Air Development Center, Griffith Air Force Base, N.Y.

48. Measuring Equivalent Circuits by J. C. Hogan, Professor of Electrical Engineering, University of Missouri, Columbia, Missouri, and V. E. Verrall, System Planning and Protection Engineering, Central nlinois Public Service Company, Springfield, Illinois. Reprinted from Volume XXII, Proceedings of the American Power Conference.

49. Dewatering Rates For Digested Sludge in Lagoons by Edgar A. Jeffrey, Assistant Professor of Sanitary Engineering, University of Missouri. Reprinted from Journal Water Pollution Control Federation, November 1960, Washington, 16, D. C.

50. Static Modulus of Elasticity of Concrete as Affected by Density by Adrian Pauw, P.E., Professor of Civil Engineering, University of Missouri. Reprinted from American Concrete Institute Journal, Title No. 57-32; V. 32; No. 6, December 1960 (Proceedings V. 57), P.O. Box 4754, Redford Station, Detroit 19, Michigan.

51. The Application of the Principle of Corresponding States for Polar Substances by Truman S。 Storvick, P.E., Assistant Professor of Chemical Engineering, University of Missouri, and J. Mo Smith, Northwestern University. Reprinted from Journal of Chemical and Engineering Data, Vol. 6, No. 1, January 1961.

52. Loosening of Bolted Joints by Small Plastic Deformations by O. A. Pringle, P. E., Associate Professor of Mechanical Engineering, Presented at the Winter Annual Meeting, New York, N. Y., Nov. 27 - Dec. 2 , 1960, of The American Society of Mechanical Engineers. Paper No. 60-WA-116.

53. Thermodynamic Properties of n-Propyl Alconol by J. L. Cosner, Graduate Student, Department of Chemical Engineering, University of Missouri, J. E. Gagliardo, Student Assistant in Chemical Engineering, University of Missouri and T. S. Storvick, P. E., Assistant Professor of Chemical Engineering, University of Missouri, Reprinted from Journal of Chemical \& Engineering Data, Vol. 6, No. 3 July, 1961.

54. An Evaluation of the Overhead Projector in Teaching Kinematics by Richard P. Covert, Associate Professor of Industrial Engineering, Reprinted from The Journal of Engineering Education, Vol. 51, No. 10 , June 1961.

55. Transfer of Load Between Precast Bridge Slabs by Adrian Pauw, P.E. and John E. Breen, Assistant Professor, Department of Civil Engineering, University of Missouri, Reprinted from Bulletin 279 (1961) Highway Research Board, Washington, D.C.

56. The Present Status of Structural Lightweight Concrete in the U.S.A. by Adrian Pauw, P.E., Professor of Civil Engineering, University of Missouri. Reprinted from "De Ingenieur," Vol. 73, No. 34, Aug. 25, 1961, The Netherlands.

57. Field Testing of Two Prestressed Concrete Girders by Adrian Pauw, Professor of Civil Engineering, University of Missouri, and John E. Breen, Instructor in Civil Engineering, University of Missouri. Reprinted from Highway Research Board Bulletin 307, National Academy of Sciences--National Research Council Publication 937, pages 42-63, 1961.

58. An Evaluation of the Overhead Projector in Teaching Kinematics by Richard P. Covert, Associate Professor of Industrial Engineering, University of Missouri. Reprinted from The Journal of Engineering Education, Vol. 51, No. 10, June 1961.

59. The Impedance of a Coil Placed on a Conducting Plane by T. J. Russell, The Bendix Corporation, Kansas City, Missouri, V. E. Schuster, Motorola, Inc., Phoenix, Arizona and D. L. Waidelich, Professor of Electrical Engineering, University of Missouri. Reprinted.from AIEE Winter General Meeting, New York, N. Y., January 28 - February 2, 1962. 


\section{The University of Missouri SCHOOLS AND COLLEGES}

College of ARTS AND SCIENCE

SCHOOL OF SOCIAL WORK

College of Agriculture

SCHOOL OF FORESTRY

SCHOOL OF HOME ECONOMICS

School of Business and Public Administration

COLLEGE OF EDUCATION

COLLEGE OF ENGINEERING

ENGINEERING EXPERIMENT STATION

Graduate SCHOOL

SCHOOL OF JOURNALISM

SCHOOL OF LAW

SchoOl of Medicine

SCHOOL OF NURSING

SCHOOL OF VeTERINARY MEDICINE 
University of Missouri Libraries

University of Missouri

MU Engineering Experiment Station Series

Local Identifier

Capture information

Date captured

Scanner manufacturer Ricoh

Scanner model

Scanning software

optical resolution

Color settings

File types

Source information

Format

Content type

Notes

Derivatives - Access copy

Compression

Editing software

Resolution

Color

File types

Notes Tiff

Book

Text

\section{LZW}

Russell1962

MP C4503

$600 \mathrm{dpi}$

Grayscale, 8 bit; Color 24 bit

Digitized duplicate copy not retained in collection.

Adobe Photoshop

600 dpi

Grayscale, 8 bit; Color, 24 bit

Tiffs converted to pdf

Greyscale pages cropped and canvassed. Noise removed from background and text darkened.

Color pages cropped. 